\title{
Calixarenos. I. Obtenção e Propriedades
}

\author{
Paula M. Marcos, ${ }^{*}{ }^{, A, c}$ Sandra Félix ${ }^{B, C}$
}

Este artigo descreve os compostos macrocíclicos calixarenos sob o ponto de vista da sua obtenção e propriedades. São enumeradas as condições experimentais mais apropriadas à sintese dos calixarenos precursores, assim como as reacções de funcionalização das suas coroas inferior e superior. As propriedades físicas, espectrais, conformacionais e complexantes dos calixarenos são também descritas. $O$ interesse nestes compostos aumentou quase exponencialmente nos últimos quinze anos e isto deve-se, sem dúvida, à sua extrema versatilidade para complexar e transportar iões e moléculas neutras de um modo selectivo. A relativa facilidade com que os compostos de partida podem ser sintetizados e posteriormente modificados, juntamente com a grande variedade de conformações e de tamanhos da cavidade do macrociclo, torna-os muito atractivos para aplicações industriais.

\section{BREVE INTRODUÇÃo HISTÓRICA}

Em química orgânica existem vários milhões de compostos agrupados em centenas de famílias. Uma dessas famílias é a dos calixarenos, que são compostos macrocíclicos resultantes da condensação directa de fenóis para-substituídos com formaldeído, em meio básico (Esq. 1).

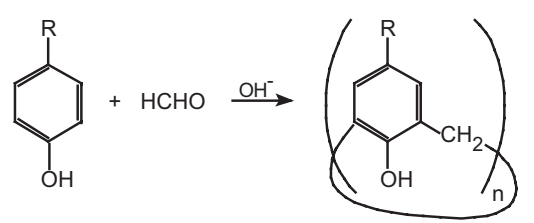

Esquema 1 Síntese geral de calixarenos

A história destes compostos faz parte da química do fenol-formaldeído, que se iniciou há mais de um século com o químico Adolph von Baeyer. Em 1872 Baeyer aqueceu pela primeira vez formaldeído aquoso com fenol, resultando um produto resinoso que não foi possível caracterizar. Trinta anos mais tarde, Leo Baekeland usou a mesma reacção para preparar uma resina elástica e resistente, que comercializou com o nome de Bakelite. Este facto fez despontar muitas pesquisas laboratoriais que se debruçaram sobre o estudo do processo de condensação. Entre elas

\footnotetext{
${ }^{\mathrm{a}}$ Faculdade de Farmácia da Universidade de Lisboa, Av. Prof. Gama Pinto, 1649-003 Lisboa pmmarcos@fc.ul.pt

b Universidade Atlântica, Antiga Fábrica da Pólvora de Barcarena, 2730-036 Barcarena

${ }^{\mathrm{c}}$ Centro de Ciências Moleculares e Materiais, FCUL, Edifício C8, 1749-016 Lisboa
}

destacaram-se, durante os anos $40 \mathrm{e}$ 50, as de Alois Zinke e Erich Ziegler, que simplificaram o problema substituindo o fenol por fenóis para-substituídos. Zinke e Ziegler condensaram vários $p$-alquilfenóis com formaldeído aquoso e hidróxido de sódio, obtendo produtos insolúveis com elevados pontos de fusão. Com base na determinação do peso molecular do acetato do produto obtido a partir do $p$-terc-octilfenol, Zinke atribuiu àqueles produtos estruturas tetraméricas cíclicas. Em 1955, John Cornforth repetiu as experiências de Zinke com dois fenóis para-substituídos (o p-terc-butil e o $p$-terc-octil), tendo isolado em cada caso um par de produtos. Estes apresentavam pontos de fusão distintos e Cornforth sugeriu que se tratava de conformações diferentes dos tetrâmeros cíclicos. Um ano mais tarde, Hayes e Hunter realizaram uma síntese em vários passos de um tetrâmero de Zinke, partindo do $p$-metilfenol. Embora não tenha sido feita nenhuma comparação directa com a substância obtida pelo procedimento de Zinke, a identidade foi assumida. Assim, no fim dos anos 50 parecia ser evidente que a reacção de Zinke produzia tetrâmeros cíclicos, embora as experiências de Cornforth tivessem mostrado que a reacção não era assim tão clara. Posteriormente, durante os anos 70, Hermann Kämmerer e John Munch realizaram estudos de RMN de protão a temperatura variável e verificaram que ocorria interconversão conformacional rápida à temperatura ambiente, rejeitando assim a hipótese de Cornforth sobre o par de compostos isolados.

No início dos anos 70, David Gutsche, interessado na construção de simuladores enzimáticos, pensou nos tetrâmeros cíclicos de Zinke como substâncias contendo cavidades apropriadas para esse fim. O seu grupo mostrou que a condensação directa de fenóis para-substituídos com formaldeído em condições básicas conduzia geralmente a misturas de oligómeros cíclicos com anéis de vários tamanhos. No caso mais estudado, usando p-terc-butilfenol, obtinham o tetrâmero (1), o hexâmero (2), o octâmero (3) e o composto dihomooxa (4), no qual uma ponte metilénica $\left(-\mathrm{CH}_{2}-\right)$ é substituída por uma oxodimetilénica $\left(-\mathrm{CH}_{2} \mathrm{OCH}_{2}-\right)$. A presença de pequenas quantidades de pentâmero e heptâmero cíclicos foi também posteriormente demonstrada.

O nome de calixareno foi sugerido por Gutsche devido à semelhança por ele encontrada entre a forma de um vaso grego (calix crater) e o modelo molecular de um dos confórmeros do tetrâmero cíclico. Assim, calix vem de vaso e areno indica a presença de anéis aromáticos. Para adaptar este nome a outros oligómeros cíclicos, o tamanho do macrociclo é indicado por um número entre parêntesis rectos, inserido entre as palavras "calix" e "areno". A natureza e a posição da substituição nos anéis aromáticos são indicadas por números e prefixos apropriados. Por exemplo, o tetrâmero 
cíclico derivado do p-terc-butilfenol é designado por 5,11,17,23-tetra-tercbutil-25,26,27,28-tetrahidroxicalix[4] areno (1) ou simplesmente p-terc-butilcalix[4]areno. Quanto ao prefixo dihomo indica a presença de dois átomos adicionais (neste caso um de carbono e outro de oxigénio) e oxa indica um átomo de oxigénio em vez de um de carbono. Ainda devido à semelhança com um vaso grego, as estruturas dos calixarenos (Esq.1) são geralmente desenhadas com os substituintes para direccionados para cima ("coroa superior") e com os grupos hidroxilo direccionados para baixo ("coroa inferior"). quantidade de base, o catião e a temperatura são factores que contribuem para determinar as selectividades e os rendimentos de formação de cada produto.

As condições experimentais para a síntese num só passo de calixarenos precursores (calixarenos contendo grupos $\mathrm{OH}$ livres) com quatro, seis e oito unidades de $p$-terc-butilfenol são hoje conhecidas e foram desenvolvidas por Gutsche e colaboradores. É possivel sintetizar os $p$-terc-butilcalix[4], [6] e [8]arenos (compostos 1, 2 e 3, respectivamente) com rendimentos, após recristalização, de aproxi-
Embora o p-terc-butilfenol seja o reagente preferido na reacção de formação dos calixarenos, têm também sido usados outros fenóis para-substituídos. Assim, fenóis contendo igualmente carbonos quaternários directamente ligados ao anel fenilo, como o $p$-terc-pentil e o $p$-terc-octilfenóis, reagem de um modo semeIhante dando calix[4], [6] e [8]arenos, embora com rendimentos menores. Fenóis como o $p$-cresol, o $p$-etilfenol, o $p$-iso-propilfenol, o $p$-fenilfenol, entre outros, também têm sido usados. Fenóis com grupos $n$-alquilo de cadeia longa em posições para têm também sido convertidos em calixarenos.

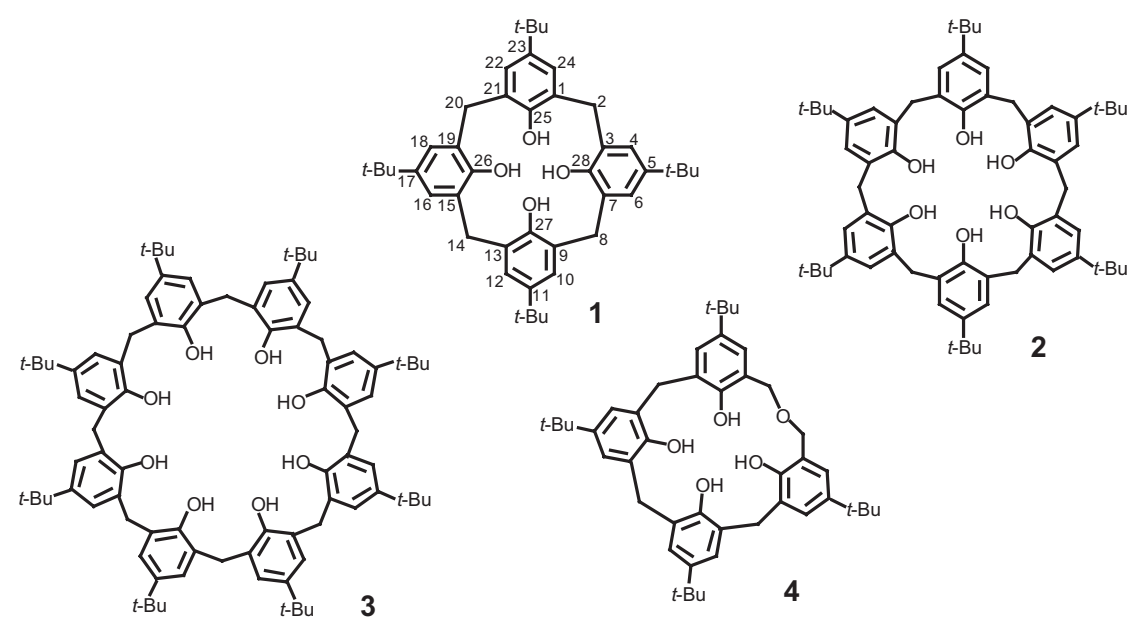

Apesar da sua longa história, as grandes potencialidades dos calixarenos em química supramolecular ${ }^{1}$ só foram descobertas num passado relativamente recente. A "era moderna" da química dos calixarenos começou lentamente nos anos 70, mas rapidamente se desenvolveu durante os anos 80 e 90, tendo atingido um crescimento quase exponencial. Hoje estes compostos representam por si só uma importante classe de hospedeiros sintéticos, para além de serem usados como "blocos de construção" na obtenção de moléculas hospedeiras altamente sofisticadas.

\section{SíNTESE DE CALIXARENOS PRECURSORES}

A condensação directa de fenóis para-substituídos com formaldeído em meio básico conduz a misturas de produtos, cujas percentagens dependem das condições experimentais. Assim, a razão molar dos reagentes, a madamente 50 , 85 e $63 \%$, respectivamente. As condições óptimas para a formação do tetrâmero são baixa concentração de base $(0,045$ moles de $\mathrm{NaOH}$ por mole de $p$-terc-butilfenol) e temperaturas altas (refluxo em éter difenílico), para o hexâmero são necessárias quantidades bastante maiores de base $(0,3$ moles $)$, catiões maiores $\left(\mathrm{K}^{+}\right.$ou $\left.\mathrm{Rb}^{+}\right)$e temperaturas mais baixas (refluxo em xileno) e finalmente o octâmero forma-se à mesma temperatura, mas com pequenas quantidades de base $(0,03$ moles de $\mathrm{NaOH}$ ). Muito menos acessíveis são os calixarenos análogos contendo um número ímpar de anéis aromáticos. Os p-terc-butilcalix[5] e [7]arenos têm sido obtidos por condensação directa, mas com rendimentos bastante inferiores (<20\%). Foram recentemente isolados e caracterizados por RMN e espectrometria de massa todos os calixarenos contendo de 9 a 20 unidades fenólicas. Quanto ao p-terc-butildihomooxacalix[4]areno (4), é hoje obtido em cerca de $24 \%$ e através de um procedimento mais simplificado.

\section{Propriedades}

PropRIEDAdes FísICAS E ESPECTRAIS

Os calixarenos são caracterizados por terem pontos de fusão muito elevados, geralmente acima de $300{ }^{\circ} \mathrm{C}$, sendo mesmo superior a $400{ }^{\circ} \mathrm{C}$ para o $p$-terc-butilcalix[8]areno. Os pontos de fusão dos $p$-terc-butilcalixarenos aumentam, em geral, com o aumento do tamanho do anel, tendo os compostos ímpares valores inferiores aos pares. Esta tendência não se verifica porém para os calixarenos com maior número de unidades fenólicas ( $\mathrm{n} \geq$ 10). Os substituintes em posição para podem influenciar bastante o ponto de fusão, assim como os introduzidos na coroa inferior do calixareno, através de reacções nos grupos hidroxilo. Outra característica dos calixarenos é a sua insolubilidade em água, mesmo em condições básicas, e a baixa solubilidade em solventes orgânicos. Embora isto dificulte o seu isolamento purificação e caracterização, a maioria dos calixarenos é suficientemente 
solúvel em solventes orgânicos comuns para permitir determinações espectrais. A solubilidade pode também carbonos metilénicos e duas para os carbonos do grupo terc-butilo. O espectro de protão à temperatura designou estas conformações por cone, cone parcial, 1,2-alternada e 1,3-alternada (Fig. 1).

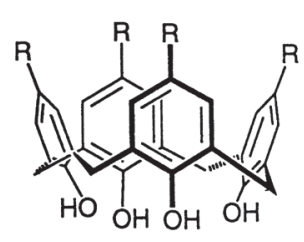

Cone

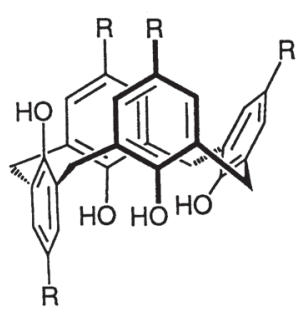

Cone parcial

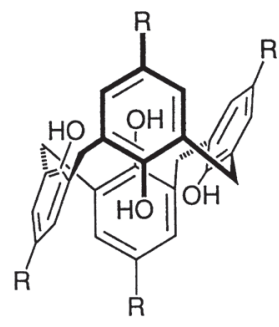

1,2-Alternada

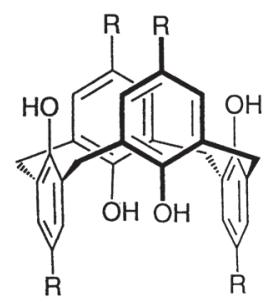

1,3-Alternada

Figura 1 Conformações mais estáveis dos calix[4]arenos

ser significativamente alterada pelos substituintes para e pelos introduzidos na coroa inferior. O comportamento físico dos calixarenos precursores é principalmente determinado pelas ligações de hidrogénio intramoleculares existentes entre os grupos $\mathrm{OH}$. Nos calix[4]arenos estas ligações são particularmente fortes, afectando a acidez daqueles grupos. A dissociação do primeiro protão ocorre a valores de $\mathrm{pH}$ bastante baixos, comparativamente aos valores dos correspondentes fenóis, enquanto que os $\mathrm{p} K_{\mathrm{a} 2}-\mathrm{p} K_{\mathrm{a} 4}$ apresentam valores iguais ou superiores. A facilidade com que aquela dissociação ocorre é atribuída à forte estabilização do monoanião resultante por ligações de hidrogénio. Quanto à dissociação do segundo protão, esta é já menos facilitada devido às repulsões electrostáticas desfavoráveis que prevalecem sobre a estabilização do dianião por ligações de hidrogénio.

Os calixarenos exibem absorções de alongamento dos grupos $\mathrm{OH}$ a frequências bastante baixas, geralmente entre $3100-3300 \mathrm{~cm}^{-1}$, devido às ligações de hidrogénio intramoleculares. A força destas ligações pode ser estabelecida por IV, verificando-se que são mais fortes para os calix[4], [6] e [8]arenos e mais fracas para os calix[5] e [7]arenos. Com o aumento do número de unidades fenólicas $(n>8)$, a flexibilidade das moléculas aumenta, observando-se um enfraquecimento daquelas ligações. A simetria dos calixarenos conduz a espectros de RMN mais simples do que os dos correspondentes oligómeros lineares. Para os $p$-terc-butilcalix[n]arenos, o espectro de ${ }^{13} \mathrm{C}$ apresenta quatro linhas paraas ressonâncias devidas aos carbonos aromáticos, uma para os ambiente do p-terc-butilcalix[4]areno exibe singuletos para as ressonâncias dos protões aromáticos, terc-butilo e hidroxilo e exibe um par de dupletos para os protões $\mathrm{CH}_{2}$, o qual representa o aspecto mais interessante do espectro. Os calix[8]arenos comportam-se de um modo semelhante. Os calix[6]arenos mostram apenas um singuleto à temperatura ambiente para os protões $\mathrm{CH}_{2}$ e os de índice ímpar apresentam espectros de protão em solventes não polares mais próximos destes últimos. $O$ desvio químico do grupo $\mathrm{OH}$ reflecte também a força das ligações de hidrogénio intramoleculares, sendo tanto maior quanto mais fortes forem essas ligações. A espectrometria de massa, embora fornecendo menos informação estrutural do que a cristalografia de raios- $X$ ou a espectroscopia de RMN, tem continuado a ser utilizada, principalmente na determinação de pesos moleculares de calixarenos com $\mathrm{n}>8$. Várias centenas de determinações cristalográficas de raios- $X$ de calix[4] arenos têm sido apresentadas, mas relativamente poucas estruturas de calixarenos maiores têm sido obtidas.

\section{Propriedades CONFORMACIONAIS}

Um dos aspectos mais interessantes dos calixarenos reside na variedade de conformações que podem assumir. A possibilidade dos calix[4]arenos poderem existir em quatro conformações mais estáveis, resultantes da inversão dos anéis fenilo relativamente ao plano médio da molécula, foi pela primeira vez proposta por Cornforth em 1955. Posteriormente, Gutsche
À medida que o número de grupos arilo aumenta, o número de conformações mais estáveis aumenta também. Embora os calix[5]arenos exibam apenas os mesmos quatro confórmeros que os calix[4]arenos, os calix[6]arenos apresentam oito, os calix[8]arenos dezasseis, etc. As estruturas cristalinas dos calix[4] e [5]arenos contendo grupos $\mathrm{OH}$ livres adoptam uma conformação cone, a qual é estabilizada por ligações de hidrogénio intramoleculares. Para os calix[6]arenos foram observadas duas conformações no estado sólido: uma onde todos os grupos $\mathrm{OH}$ estão de um mesmo lado da molécula e outra onde três grupos adjacentes estão para cima e os outros três para baixo. Os calix[7] e os [8]arenos apresentam conformações nas quais os grupos $\mathrm{CH}_{2}$ se desviam alternadamente para cima e para baixo do plano médio da molécula, formando uma espécie de círculo pregueado.

Todos os calixarenos contendo grupos $\mathrm{OH}$ livres (calixarenos precursores) são conformacionalmente móveis em solução e à temperatura ambiente. Através do estudo de $\mathrm{RMN}{ }^{1} \mathrm{H}$ de temperatura variável, Kämmerer mostrou que as quatro conformações de um calix[4]areno eram facilmente interconvertíveis. Verificou que a ressonância dos protões metilénicos em clorofórmio aparecia como um par de dupletos a $20^{\circ} \mathrm{C}$, os quais colapsavam para um singuleto quando a temperatura atingia os $60{ }^{\circ} \mathrm{C}$. Este comportamento é interpretado em termos de uma interconversão entre uma conformação cone e a sua imagem especular, que ocorre rapidamente a altas temperaturas mas lentamente a baixas temperaturas 
(Fig.2). A altas temperaturas o protão equatorial original $\left(\mathrm{H}_{\mathrm{B}}\right)$ transforma-se em axial e vice-versa, resultando

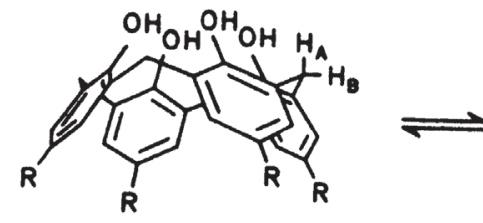

Figura 2 Interconversão da conformação cone num calix[4]areno

no espectro de protão apenas um sinal médio. A flexibilidade conformacional dos calixarenos com grupos $\mathrm{OH}$ na coroa inferior é determinada pelo tamanho do anel, o qual influencia a natureza das ligações de hidrogénio intramoleculares. A conformação cone é a preferida para os calix[4] e [5]arenos em solução, apresentando fortes ligações de hidrogénio intramoleculares. Os calix[8]arenos adoptam uma conformação em círculo pregueado, que surpreendentemente apresenta ligações de hidrogénio igualmente fortes. Os outros calixarenos apresentam conformações que possuem características destas duas, verificando-se no entanto que à medida que o tamanho do anel aumenta as conformações preferidas dos calixarenos vão-se tornando mais planares.

As temperaturas de coalescência, assim como as barreiras de energia para a inversão do anel, podem ser determinadas através de estudos dinâmicos de RMN de protão. Os substituintes em posição para têm pouca influência na barreira de energia dos calixarenos. Esta indiferença está de acordo com o movimento de inversão conformacional que envolve a rotação dos grupos $\mathrm{OH}$ através do interior do anel, colocando para fora os substituintes para. Nos calix[4]arenos o outro movimento possível, através da coroa superior (grupos para), está impedido mesmo para substituintes tão pequenos como o hidrogénio. A polaridade do solvente já tem mais influência na inversão conformacional dos calixarenos, principalmente no caso dos calixarenos maiores. Quando se passa de um solvente pouco polar como o clorofórmio para solventes mais polares como a acetona ou o acetonitrilo, observa-se uma diminuição significativa na barreira de inversão, diminuindo esta ainda mais num solvente básico como

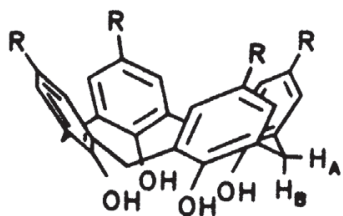

a piridina, capaz de estabelecer ligações de hidrogénio com os grupos hidroxilo.

Os calixarenos têm capacidade para incluir diversas espécies químicas, mas não possuem cavidades rígidas devido a serem conformacionalmente móveis, como já foi mencionado. É por isso necessário fixá-los, impedindo a inversão conformacional pelas duas vias possíveis (rotação das coroas inferior ou superior através do anel). Isto consegue-se introduzindo grupos substituintes suficientemente grandes nas coroas ou estabelecendo pontes através de uma ou ambas as coroas. Nos calix[4] arenos a rotação das unidades arilo é impedida pela substituição dos átomos de hidrogénio das funções $\mathrm{OH}$ por grupos maiores do que o etilo, sendo assim possível fixar as quatro conformações e isolá-las como confórmeros estáveis. Estes confórmeros podem ser facilmente distinguidos através do RMN de protão (tabela 1).

\section{Síntese de calixarenos FUNCIONALIZADOS}

Os calixarenos podem ser funcionalizados quer ao nível da coroa inferior, quer ao nível da coroa superior. De facto, a utilização dos calixarenos nas suas mais diversas aplicações depende de modificações apropriadas realizadas nos compostos precursores.

A substituição dos átomos de hidrogénio das funções $\mathrm{OH}$ por outros grupos pode ser feita por esterificação ou eterificação. Os ésteres foram os primeiros derivados de calixarenos modificados na coroa inferior a serem obtidos. A esterificação pode dar-se em todos os grupos $\mathrm{OH}$ de um calixareno, usando excesso de reagente. Deste modo, a acetilação e a aroilação têm sido feitas com cloreto de acetilo ou cloreto de benzoílo, respectivamente, na presença de piridina, $\mathrm{NaH}$ ou de $\mathrm{AlCl}_{3}$. A acetilação tem também sido conseguida com anidrido acético e na presença de $\mathrm{H}_{2} \mathrm{SO}_{4}$. A esterificação parcial também tem ocorrido através do uso de halogenetos de ácidos em presença de bases mais fracas, usando quantidades limitantes do reagente e / ou pelo uso de

Tabela 1 Características espectrais de RMN ${ }^{1} \mathrm{H}$ para os confórmeros de derivados do $p$-terc-butilcalix[4]areno

\begin{tabular}{|l|l|l|l|}
\hline Conformação & \multicolumn{1}{|c|}{ ArH } & \multicolumn{1}{|c|}{$\mathrm{CH}_{2}$} & \multicolumn{1}{|c|}{$\mathrm{C}_{\left(\mathrm{CH}_{3}\right)_{3}}$} \\
\hline Cone & 1 singuleto & 1 par dupletos & 1 singuleto \\
\hline Cone parcial & $\begin{array}{l}\text { 2 singuletos e } \\
\text { 2 dupletos ou } \\
4 \text { singuletos } \\
(1: 1: 1: 1)\end{array}$ & $\begin{array}{l}\text { 2 pares dupletos }(1: 1) \text { ou 1 } \\
\text { par dupletos e 1 singuleto } \\
(1: 1)\end{array}$ & $\begin{array}{l}\text { 3 singuletos } \\
(1: 2: 1)\end{array}$ \\
\hline 1,2-Alternada & $\begin{array}{l}2 \text { singuletos } \\
(1: 1)\end{array}$ & $\begin{array}{l}\text { 1 singuleto e } \\
\text { 2 dupletos (1:1) } \\
1 \text { singuleto }\end{array}$ & 1 singuleto \\
\hline 1,3-Alternada & 1 singuleto & singuleto \\
\hline
\end{tabular}

O carbono-13 é também bastante importante na identificação conformacional dos calix[4]arenos, através da chamada "regra de Mendoza". Este verificou que quando dois anéis arilo adjacentes estão numa orientação syn (ambos para o mesmo lado) a ressonância do grupo $\mathrm{ArCH}_{2} \mathrm{Ar}$ aparece a cerca de 31 ppm e quando estão numa orientação anti (um para cima, um para baixo) aquela aparece a cerca de 37 ppm. Esta "regra" tem também sido aplicada com sucesso a calix[5] e [6]arenos. reagentes mais volumosos. A alquilação completa dos grupos $\mathrm{OH}$ é conseguida se se usarem reagentes suficientemente reactivos. Um método útil para a obtenção de éteres é fazer reagir os calixarenos com halogenetos de alquilo em refluxo de THF/DMF na presença de $\mathrm{NaH}$. Deste modo, têm sido preparados vários éteres metílicos, etílicos, propílicos, alílicos, benzílicos, entre outros. Esta reacção tem sido estudada detalhadamente para os calix[4]arenos, mas também para calixarenos de índice superior. A 
eterificação parcial tem também sido obtida. A monoalquilação de calix[4] arenos tem-se conseguido por diversos métodos, como por exemplo com excesso de agente alquilante e 0,6 equivalentes de $\mathrm{K}_{2} \mathrm{CO}_{3}$ em MeCN ou 1,2 equiv. de CsF em DMF. $\mathrm{O}$ uso de diazometano e de tosilatos tem conduzido a produtos 1,3-di-substituídos. Também as reacções de halogenetos de alquilo com o p-terc-butilcalix[4] areno na presença de $\mathrm{K}_{2} \mathrm{CO}_{3}$ (2 equiv.) produzem apenas o diéter-1,3. Contudo, a reacção deste calixareno com quatro equiv. de cloridrato de 2-clorometilpiridina na presença de $\mathrm{NaH}$ deu como principal produto $(70 \%)$ e pela primeira vez, o diéter-1,2. A dialquilação alternada $(1,3)$ é bastante mais fácil de conseguir do que a dialquilação próxima $(1,2)$. Outros diéteres próximos têm também sido obtidos por métodos de protecção-desprotecção. Os calix[5], [6] e [8]arenos têm também sido parcialmente alquilados. Halogenetos de alquilo substituídos do tipo $\mathrm{XCH}_{2} \mathrm{CO}_{2} \mathrm{R}, \mathrm{XCH}_{2} \mathrm{COR}$ e $\mathrm{XCH}_{2} \mathrm{CONR}_{2}$ também têm sido usados, conduzindo respectivamente a derivados (5) com grupos éster, cetona e amida. A partir destes, uma variedade de outros produtos têm sido obtidos, como ácidos carboxílicos, cloretos de ácidos, tioamidas, etc. Alquilações com halogenetos de metilarilo contendo heteroátomos têm também sido realizadas, como é o caso dos éteres metilpiridilo já mencionados.

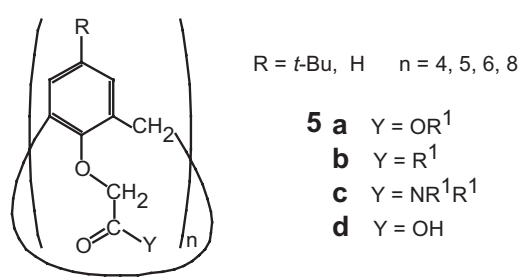

Outro modo de transformar a coroa inferior de um calixareno é ligando dois grupos hidroxilo através de pontes. $O$ primeiro exemplo surgiu em 1983 com o tratamento do $p$-terc-butilcalix[4] areno com o ditosilato do pentaetilenoglicol, obtendo-se a calixcoroa $6(\mathrm{Y}=\mathrm{H}, \mathrm{n}=5)$. Desde então têm surgido muitos outros exemplos de calixcoroas com vários comprimentos de cadeia ( $n$ ) e diferentes grupos $\mathrm{Y}$, como $\mathrm{H}$, acilo, alquilo, alilo e etoxicarbonilmetilo. Calixarenos com uma segunda ponte to tipo 1,3- (7) ou 1,2-calix[4]-bis-coroas (8) e calixaza-
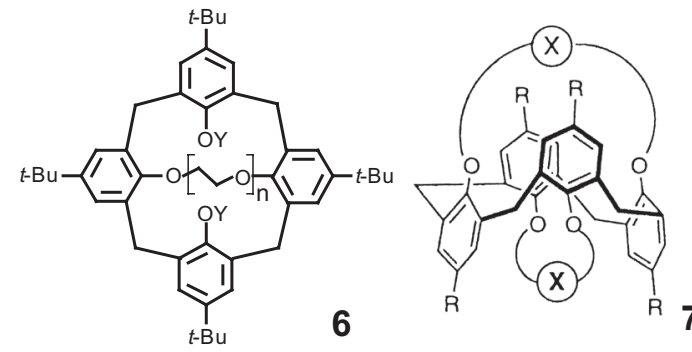

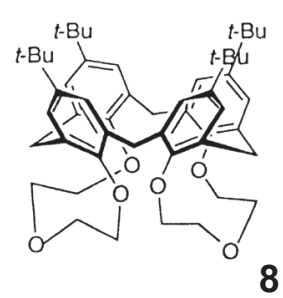

coroas têm também sido sintetizados. Recentemente, têm surgido derivados coroas de calix[5], [6] e [8]arenos. As reacções de calixarenos com reagentes bifuncionais podem conduzir, através da formação de pontes, a outras moléculas macrocíclicas mais complexas, como calixesferandos, calixcriptandos, calixarenos duplos (9) e triplos (10) ligados por uma variedade de espaçadores, incluindo éteres de coroa. Os grupos $\mathrm{OH}$ dos calixarenos têm ainda sido parcial ou totalmente substituídos por hidrogénio, $\mathrm{NH}_{2} \mathrm{e} \mathrm{SH}$. radas vias alternativas para a funcionalização em posições para, como por exemplo o rearranjo de Claisen e a via da $p$-quinonametileno. No primeiro caso (Esq. 3) o éter tetraalílico é refluxado em $N, N$-dietilanilina sofrendo rearranjos de $p$-Claisen para dar o $p$-alilcalix[4]areno com bom rendimento. Este calixareno pode ser convertido no $p$-tolueno-sulfonato, o qual por sua vez tem sido transformado numa variedade de calix[4]arenos funcionalizados.

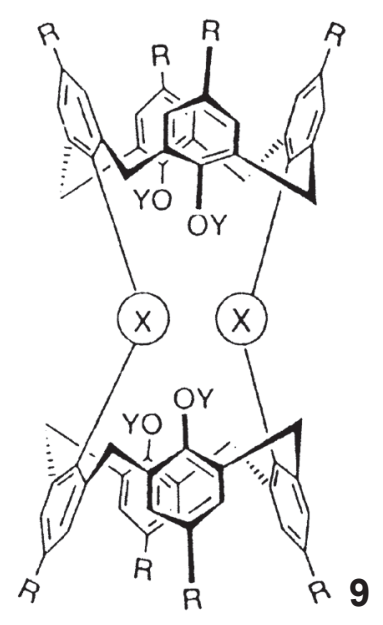

A introdução de grupos funcionais em posições para nos anéis fenólicos inicia-se pela desalquilação dos $p$-terc-butilcalixarenos. O grupo terc-butilo pode ser facilmente removido por uma reacção de Friedel-Crafts inversa ou transalquilação catalisada por $\mathrm{AlCl}_{3} \mathrm{e}$ na presença de um aceitador apropriado, como o tolueno. A introdução directa de grupos funcionais através de reacções de substituição electrófila tem porém encontrado algumas dificuldades, pelo que na maior parte dos casos as reacções dão-se em derivados éteres alquílicos (principalmente o éter metílico). A sulfonação e a nitração têm sido conseguidas directamente e os derivados nitro têm ainda sido obtidos a partir dos calixarenos sulfonados (Esq. 2). Têm sido explo-
A remoção do grupo tosilo pode depois ser efectuada com uma base alcoólica aquosa. A aplicação deste método a calixarenos maiores tem obtido fracos rendimentos. A via da p-quinonametileno (Esq. 4) envolve aminometilação, seguida de quaternização, eliminação e adição de um nucleófilo ao intermediário quinonametileno formado, permitindo assim a introdução de diferentes substituintes. Para além de ser uma via mais curta, pode ser também eficientemente aplicada a calixarenos de índice superior ( $n=4$ a 8). Têm também sido descritas substituições parciais e sido desenvolvidos métodos de funcionalização selectiva na coroa superior dos calixarenos. 


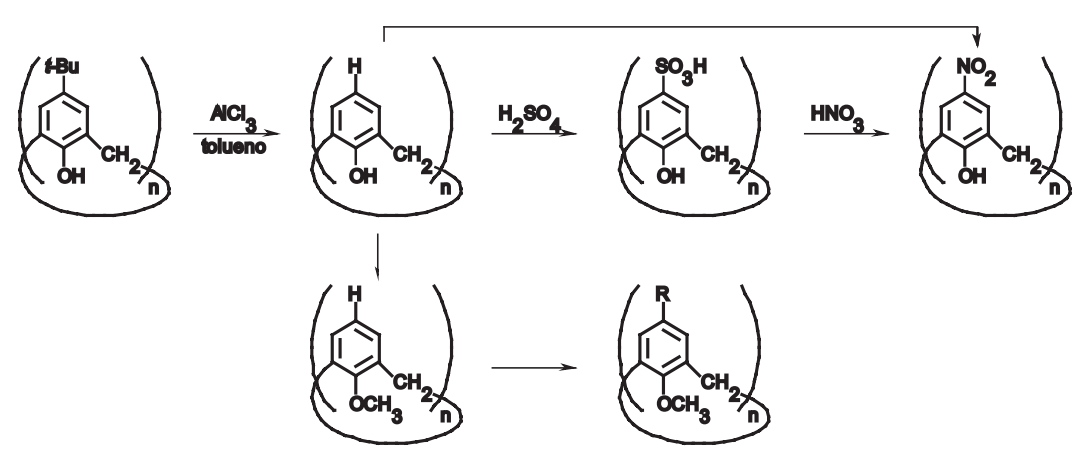

Esquema 2 Funcionalização da coroa superior de calixarenos

A introdução de vários tipos de pontes tem também ocorrido na coroa superior, essencialmente de calix[4]arenos, ligando duas posições para. Calixarenos duplos unidos pelas coroas superiores têm também sido descritos.

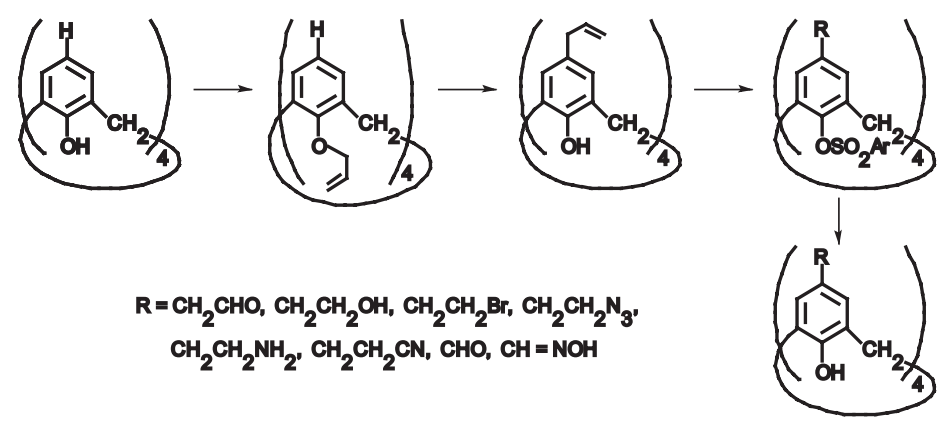

Esquema 3 Rearranjo de Claisen em calix[4]arenos

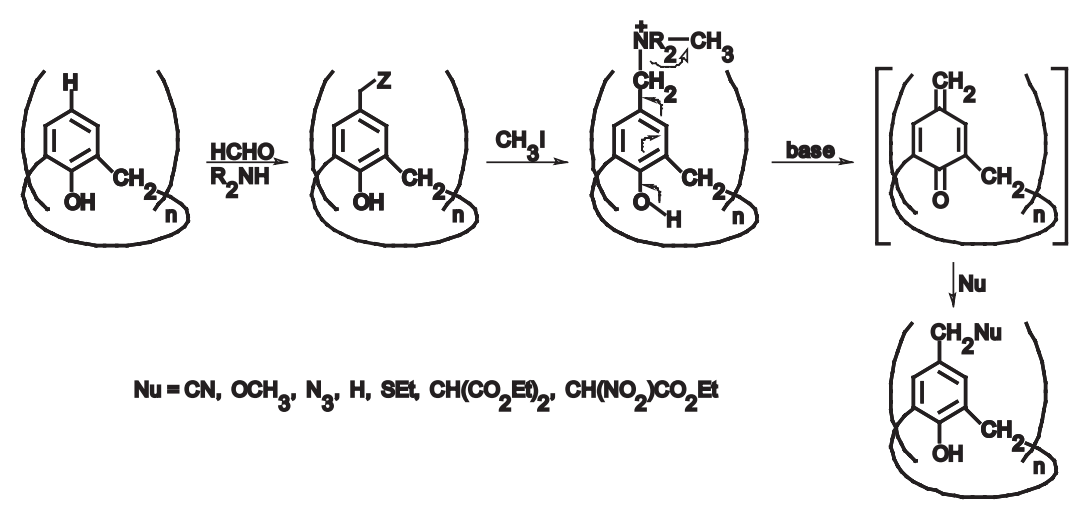

Esquema 4 Via da $p$-quinonametileno em calix[n]arenos

Modificações importantes do esqueleto dos calixarenos são ainda a oxidação das unidades fenólicas a $p$-quinonas e a completa oxidação das pontes metilénicas a grupos carbonilo, com a subsequente redução, em ambos os casos, a grupos hidroxilo.

\section{Calixarenos quirais}

Um dos principais interesses nos calixarenos como moléculas hospedeiras é a sua potencial capacidade para re-

conhecimento quiral. Os calixarenos podem ser convertidos em derivados quirais através da introdução de substituintes quirais nas coroas inferior ou superior dos macrociclos. Estes compostos podem apresentar outro 


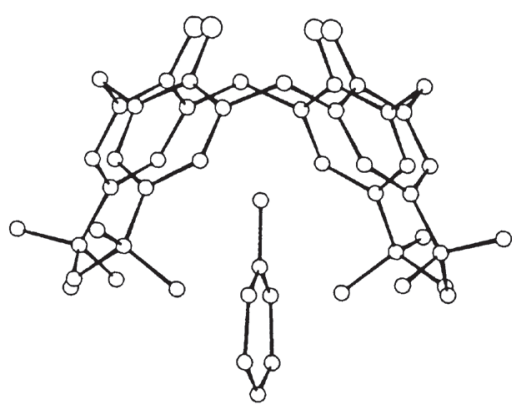

(a)

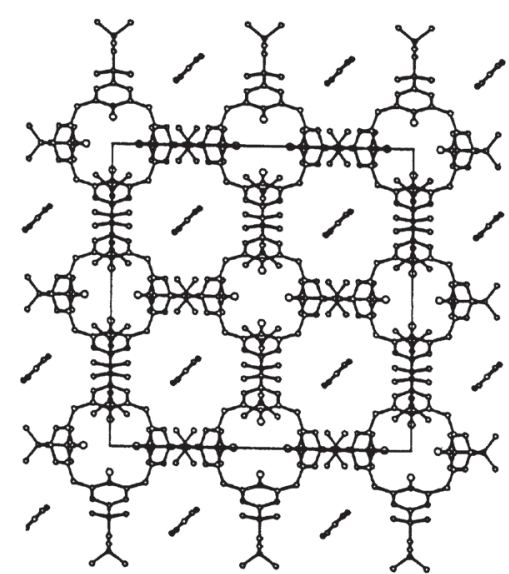

(b)

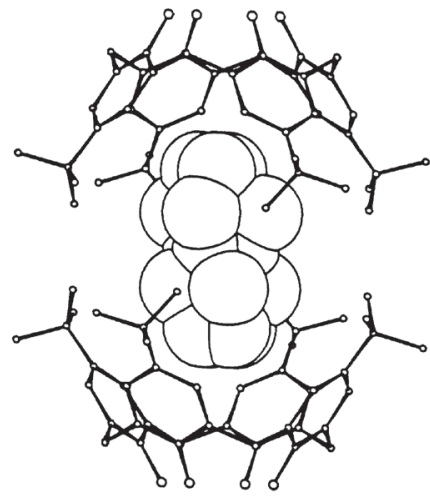

(c)

Figura 3 Estruturas cristalográficas de raios-X. (a) Complexo endo-calix tolueno- $p$-terc-butilcalix[4]areno, (b) complexo exo-calix tolueno-p-(1,1,3,3-tetrametilbutil)calix[4]areno,

(c) complexo endo-calix duplo anisol- $p$-terc-butilcalix[4]areno (Reproduzidas da Ref. 1)

No estado sólido o comportamento de inclusão destes compostos depende de vários factores, como sejam o tamanho do macrociclo, a natureza dos seus substituintes para e a rigidez conformacional. Os grupos terc-butilo, por exemplo, desempenham um papel fundamental na formação de complexos intramoleculares com moléculas aromáticas. Estes substituintes não são suficientemente grandes de modo a ocupar a cavidade do calixareno e a existência de interacções $\mathrm{CH}_{3}-\pi$ entre os grupos metilo e o anel aromático das moléculas incluídas aumenta a estabilidade dos complexos.

Durante os anos 90 foram obtidos complexos 1:1 e 1:2 entre o fulereno $\mathrm{C}_{60}$ e os calix[8] e [5]arenos, respectivamente. Para além dos complexos com moléculas neutras, têm sido descritos outros com catiões metálicos, nomeadamente metais de transição, lantanídeos e actinídeos. Têm sido também determinadas as estruturas cristalográficas de raios $X$ de calixarenos funcionalizados na coroa inferior. Todos os calix[4]arenos do tipo 5 adoptam, no estado sólido, uma conformação cone distorcida, com os grupos carbonilo a apontarem para fora da cavidade. Foi determinada a estrutura cristalina do complexo $\mathrm{K}^{+}-p$ terc-butilcalix[4]areno tetraacetamida, a qual se apresenta mais simétrica do que a do ligando livre, encontrando-se o ião $\mathrm{K}^{+}$no centro da cavidade formada pelos oito átomos de oxigénio (Fig.4a).

\section{CompleXaÇão EM SOLUÇão}

Uma das características mais importantes dos calixarenos é sem dúvida a sua capacidade para incluir e transportar iões e moléculas neutras de um modo selectivo. Contrariamente ao que acontece no estado sólido, em soluções aquosas neutras os calixarenos precursores exibem pouca ou nenhuma actividade ionofórica relativamente a catiões metálicos. Assim, em solução são os seus derivados que se tornam importantes moléculas hospedeiras.

Um grande número de calixarenos funcionalizados na coroa inferior (compostos 5) têm sido sintetizados e as suas capacidades complexantes estudadas em detalhe através de experiências de extracção, de transporte através de membranas líquidas e da determinação de constantes de estabilidade. Os principais factores investigados e que influenciam o poder complexante de um calixareno são o seu tamanho, a sua conformação e a natureza dos grupos substituintes na coroa inferior. As conclusões mais significativas encontradas para aqueles derivados são as seguintes:

- Ésteres: (i) Os calix[4], [5] e [6] arenos mostram preferência pelos catiões alcalinos relativamente aos alcalino-terrosos; (ii) os calix[4] arenos são selectivos ao ião $\mathrm{Na}^{+}$; (iii) a natureza do substituinte $R$ no grupo éster $\left(\mathrm{CO}_{2} \mathrm{R}\right)$ dos calix[4] arenos influencia a selectividade de complexação; (iv) os calix[5] arenos preferem os catiões $\mathrm{K}^{+}, \mathrm{Rb}^{+}$ e $\mathrm{Cs}^{+}$exibindo, no entanto, pouca discriminação entre eles; (v) os calix[6]arenos mostram preferência pelo ião $\mathrm{Cs}^{+}$, enquanto que os calixarenos maiores (calix[7] e [8] arenos) são ineficazes.

- Cetonas: as cetonas são ligandos semelhantes, mas mais fortes do que os ésteres.

- Amidas: (i) as tetraamidas terciárias extraem e complexam mais fortemente os iões alcalinos e os alcalino-terrosos do que os ésteres e cetonas, mas de um modo menos selectivo do que os ésteres; (ii) as amidas são agentes complexantes mais fortes para os catiões alcalino-terrosos do que para os alcalinos.

- Ácidos carboxílicos: os calix[4] arenos complexam os iões dos metais alcalinos e, principalmente, os alcalino-terrosos de um modo muito mais forte do que as correspondentes amidas, exibindo uma grande selectividade $\mathrm{Ca}^{2+} / \mathrm{Mg}^{2+}$.

- A remoção dos grupos terc-butilo da posição para tem um efeito significativo nas capacidades complexantes de calix[6]arenos ésteres e amidas.

- Derivados com funcionalidades mistas representam outra possibilidade de ajuste das propriedades de complexação.

- Relativamente às propriedades de transporte, na série dos derivados éster etílico verifica-se que o calix[4]areno exibe uma velocidade de transporte máxima para 
o $\mathrm{Na}^{+}$, que os calix[5] e [6]arenos são transportadores eficientes com uma velocidade máxima para o $\mathrm{Na}^{+}$e o $\mathrm{Cs}^{+}$respectivamente, e que o calix[8]areno é um mau transportador.

- As tetraamidas (dietil e pirrolidinil) são melhores transportadores do que os ésteres, mostrando preferência pelos iões $\mathrm{K}^{+} \mathrm{e} \mathrm{Li}^{+}$.

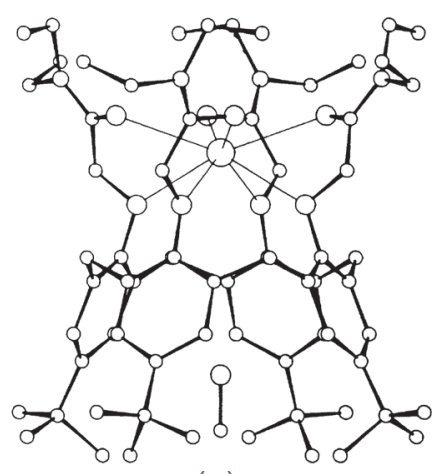

(a) renos. Derivados contendo átomos dadores de fósforo têm-se revelado extractantes altamente eficazes para lantanídeos e actinídeos. Derivados calix[4]coroa do tipo $6(n=4)$ complexam selectivamente o ião $\mathrm{K}^{+}$, enquanto que derivados com coroas maiores $(\mathrm{n}=5)$ preferem o ião $\mathrm{Cs}^{+}$. Os mais importantes são derivados $\operatorname{com} Y=$ $n$-Pr, $i$-Pr ou $n$-octil, que se encontram

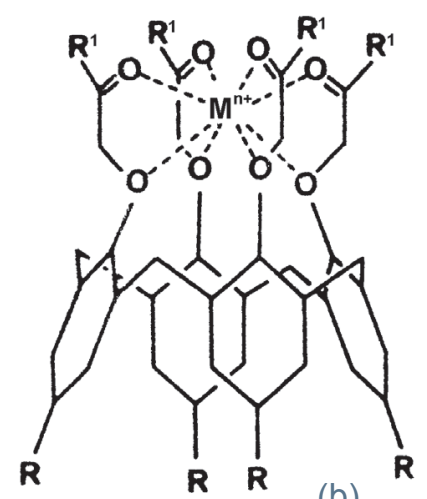

(b)

Figura 4 (a) Estrutura cristalográfica de raios-X do complexo (1:1) $\mathrm{K}^{+}$-p-terc-butilcalix[4]areno tetraacetamida (Reproduzida da Ref. 1); (b) Localização de um catião no centro da cavidade hidrófila de um calix[4]areno contendo grupos carbonilos

A partir da determinação da estrutura cristalográfica do complexo $\mathrm{K}^{+}-\mathrm{p}$ terc-butilcalix[4]areno tetraacetamida (Fig.4a), tem sido assumido com base em medidas de RMN que todos os complexos 1:1 análogos têm uma estrutura semelhante em solução. Assim, os calix[4] e [5]arenos existem numa conformação cone e formam complexos com os catiões metálicos, os quais se encontram no interior da cavidade formada pelos átomos de oxigénio fenólicos e carbonílicos (Fig. 4b).

Catiões de transição, pesados, lantanídeos e actinídeos têm também sido extraídos e complexados por estes compostos. $\mathrm{Mn}^{2+}, \mathrm{Fe}^{2+}, \mathrm{Co}^{2+}, \mathrm{Ni}^{2+}$, $\mathrm{Cu}^{2+}, \mathrm{Fe}^{3+}, \mathrm{Cr}^{3+}, \mathrm{Ag}^{+}, \mathrm{Cd}^{2+}, \mathrm{Hg}^{2+}, \mathrm{Pb}^{2+}$, $\mathrm{Pr}^{3+}, \mathrm{Eu}^{3+}, \mathrm{Tb}^{3+}, \mathrm{Yb}^{3+}$ e $\mathrm{Th}^{4+}$ encontram-se entre os mais estudados. Derivados contendo átomos dadores de azoto (grupo piridilo) e enxofre (tioamidas) também têm sido estudados e mostram afinidade essencialmente para metais de transição e pesados. Derivados de calix[5] e [6]arenos com grupos sulfonados em posição para e grupos carboxílicos na coroa inferior, complexam selectivamente o ião $\mathrm{UO}_{2}{ }^{2+}$ presente na água do mar. Isto deve-se ao facto daquele ião formar complexos com uma geometria pseudo planar penta ou hexacoordenada, a qual é fornecida por aqueles calixa- numa conformação 1,3-alternada fixa. Os calixarenos podem também formar complexos com catiões orgânicos, como alquilamónio e guanidínio e com moléculas neutras, como clorofórmio e hidrocarbonetos aromáticos.

As propriedades complexantes de calixarenos funcionalizados na coroa superior têm sido muito menos estudadas. Há, no entanto, exemplos de calix[4], [5] e [6]arenos com grupos $\mathrm{CH}_{2} \mathrm{CH}_{2} \mathrm{NH}_{2}, \mathrm{SO}_{3} \mathrm{H}, \mathrm{CH}_{2} \mathrm{PO}_{3} \mathrm{H}_{2}$, bipiridilo, entre outros, na coroa superior, que interactuam essencialmente com metais de transição.

Nos últimos anos, o desenvolvimento de calixarenos receptores de aniões tem sofrido um avanço notável. A complexação selectiva de aniões pode ser mais difícil do que a de catiões, devido às propriedades intrínsecas dos aniões (tamanho, geometria, dependência do pH e solvatação). Contudo, têm surgido diferentes tipos de receptores através da introdução, no esqueleto calixarénico, de unidades carregadas positivamente ou deficientes em electrões. Calixarenos neutros também complexam aniões selectivamente, através de ligações de hidrogénio. Vários tipos de aniões (esféricos, tetraédricos e planares) têm sido estudados com estes macrociclos.

\section{Outras aplicações}

Como é evidenciado ao longo deste artigo, uma das características mais importantes dos calixarenos é a sua diversidade. Os calixarenos têm tido aplicações como catalisadores, como sensores (eléctrodos selectivos, sensores cromogénicos e fluorescentes, compostos com não linearidade óptica), em separações iónicas e moleculares, como estruturas modelo para estudos biomiméticos, entre outras. A relativa facilidade com que os calixarenos podem ser sintetizados e posteriormente modificados, juntamente com a grande variedade de tamanhos da cavidade do macrociclo, torna-os muito atractivos para aplicações industriais. Foram já registadas mais de 300 patentes descrevendo aplicações de moléculas baseadas em calixarenos. Muitas destas patentes relacionam-se com as suas propriedades sequestradoras de metais. A mais antiga foi registada em 1984 e descreve um processo para recuperação de césio a partir de desperdícios radioactivos. Outras patentes descrevem a recuperação de urânio de soluções aquosas. Metais de transição, preciosos, pesados, etc., têm também sido removidos de vários meios por derivados de calixarenos. Nos últimos anos tem surgido um vasto leque de outras patentes, que incluem o uso dos calixarenos como foto-receptores electrofotográficos, como agentes antiestáticos, antibacterianos e antioxidantes, em tintas para fotografia e para cabelo, em aditivos para gasolina, em equipamentos sensíveis à temperatura, entre outros.

De entre o grande número de exemplos de aplicações de calixarenos, destaca-se ainda o uso como sensores em eléctrodos de membrana (líquida ou PVC) selectivos de iões. É o caso do tetrametiléster do $p$-terc-butilcalix[4]areno (11) que foi utilizado com êxito na preparação de um eléctrodo selectivo ao $\mathrm{Na}^{+}$. Este apresenta excelentes características operativas (sensibilidade, estabilidade, tempos de vida e de resposta) e a selectividade é superior à exibida por eléctrodos de vidro comerciais. Outros eléctrodos selectivos a este ião foram obtidos com os derivados tetrametoxietiléster 12 e oligo-siloxano 13 . 


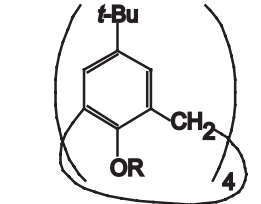

$11 \mathrm{R}=\mathrm{CH}_{2} \mathrm{CO}_{2} \mathrm{Me}$ $12 \mathrm{R}=\mathrm{CH}_{2} \mathrm{CO}_{2} \mathrm{CH}_{2} \mathrm{CH}_{2} \mathrm{OMe}$
Este último foi usado numa membrana de borracha de silicone e mostrou-se fidedigno em ensaios no soro sanguíneo e urina humanos.

\section{NotAS}

${ }^{1}$ Química Supramolecular é a química das entidades geradas através de interacções intermoleculares não covalentes. Para

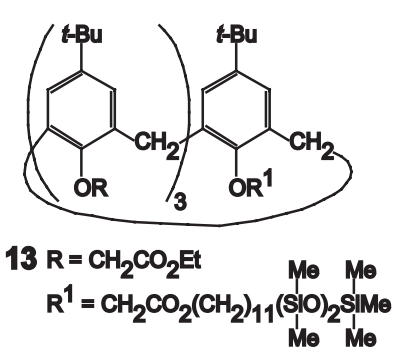

mais informação sobre o tema ver Química 79, Out-Dez. 2000 , pág. 8 e referências al mencionadas.

2 Por facilidade de linguagem, o termo complexo generalizou-se e é usado aqui não apenas no sentido estrito da química de coordenação, mas em sentido lato designando a associação molecular entre duas entidades, quaisquer que elas sejam (calixareno-catião/anião/molécula neutra).

\section{REFERÊNCIA}

[1] Calixarenes: A Versatile Class of Macrocyclic Compounds, J. Vicens e V. Böhmer (eds.), Kluwer Academic Publishers, Dordrecht, 1991.

\section{BibLIOGRAFIA}

P. M. Marcos, Síntese, Análise Conformacional e Aplicações de Dihomooxacalix [4] arenos, Tese de Doutoramento, Universidade de Lisboa, Lisboa, 1997.

C. David Gutsche, Calixarenes Revisited The Royal Society of Chemistry, Cambridge, 1998.

Calixarenes 2001, Z. Asfari, V. Böhmer, J. Harrowfield e J. Vicens (eds.), Kluwer Academic Publishers, Dordrecht, 2001.

\section{Actualidades Científicas}

\section{LASER ANTI-VÍRUS}

Uma equipa da Universidade Estadual do Arizona e do Instituto Médico John Hopkins em Baltimore, publicou em Novembro no «Journal of Physics: Condensed Matter» um artigo em que mostra que é possível sintonizar um laser de infravermelho (IV) para distinguir (e matar) organismos invasores, como vírus ou bactérias, de células humanas.

O trabalho descrito usa uma técnica de excitação vibracional denominada Impulsive Stimulated Raman Scattering (ISRS), que os autores já tinham anteriormente mostrado ser eficaz para desactivar vírus quando usavam um laser azul (radiação visível). Agora, os autores excitaram selectiva e letalmente proteínas da superfície viral ou bacteriana, destruindo-as com pulsos de laser de IV com duração de femtosegundos - um femtosegundo corresponde a $1 \times 10^{-15} \mathrm{~s}$, ou um milésimo do milionésimo do milionésimo do segundo.
Os físicos mostraram que é possível controlar o pulso do laser para evitar danificar as células humanas, muito provavelmente porque as proteínas na membrana celular e no envelope viral ou na parede celular bacteriana apresentam estrutura diferente. K. T. Tsen, da Universidade Estadual do Arizona, afirmou que «Embora não seja claro de momento porque razão há uma diferença tão grande na intensidade do laser necessária para desactivação entre células humanas e microorganismos como bactérias ou vírus, a investigação sugere que a ISRS estará pronta para ser usada em desinfecção e pode dar origem a tratamentos contra alguns dos piores muitas vezes resistentes a fármacos, patógenos virais e bacterianos».

Isto é, embora a técnica esteja longe de ser passível de aplicação directa no Homem, pode para já revelar-se muito útil na desinfecção de materiais - nomeadamente eliminando microorganismos multiresistentes -, incluindo materiais biológicos como o sangue, evitando a propagação de doenças através de sangue contaminado.

P.S.

\section{Primeira televisão com écran de MATERIAL ORGÂNICO}

A Sony anunciou o lançamento da primeira televisão comercial em que o écran é feito de OLEDs (díodos emissores de luz orgânicos). Com uma dimensão de 11 polegadas e uma espessura de apenas $3 \mathrm{~mm}$, este modelo designado por XEL-1 será colocado inicialmente à venda no Japão pelo preço de $1200 €$. Esta nova tecnologia baseia-se em materiais orgânicos que emitem luz sob efeito de uma corrente eléctrica. Combinando um baixo consumo energético, com um maior ângulo de visão que os comuns écrans de cristais líquidos, esta promete ser uma tecnologia de sucesso. A grande expectativa reside na possibilidade de vir a fabricar écrans flexíveis, em particular se o material emissor de luz a usar for um material polimérico. 


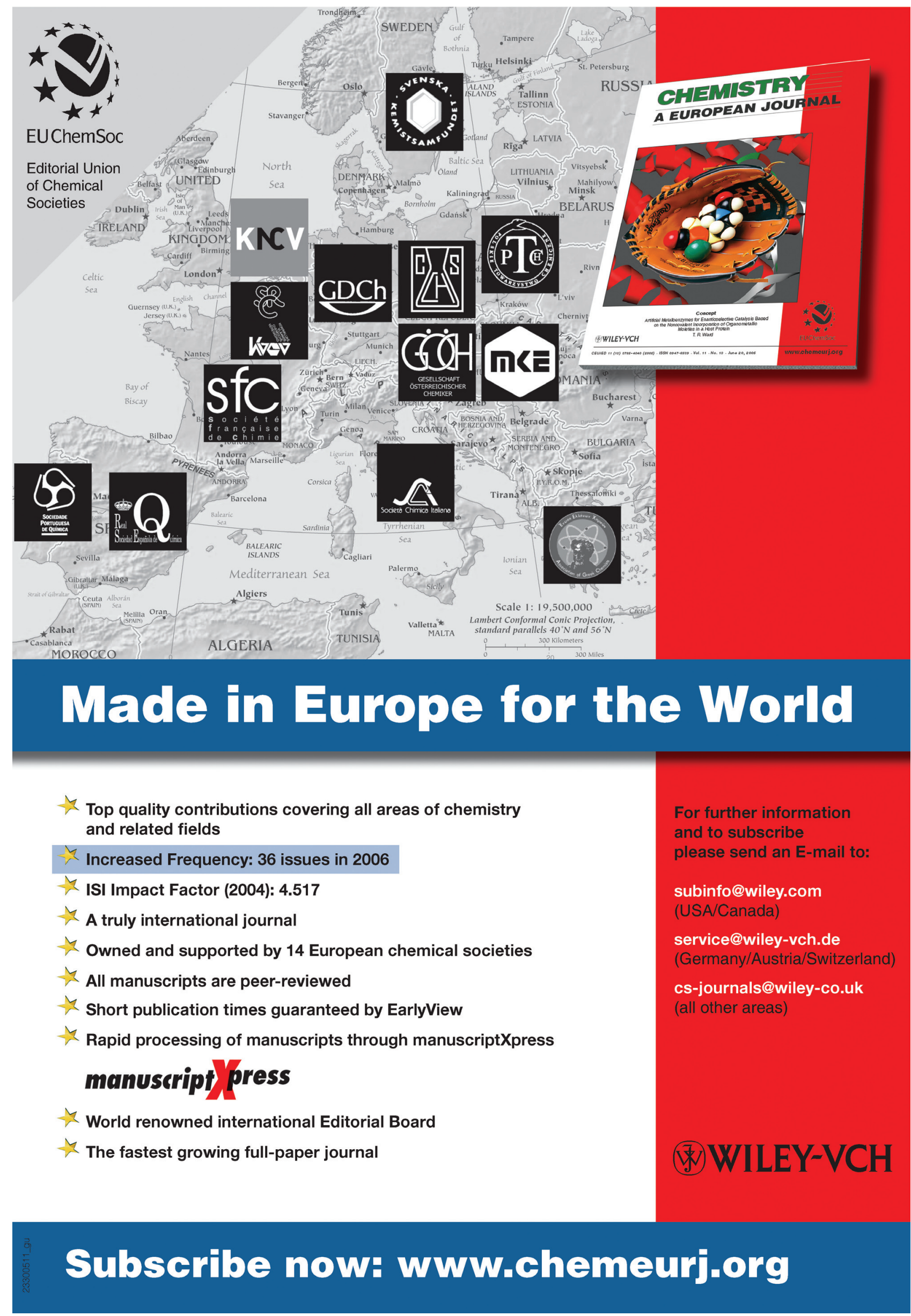

